\title{
A pesquisa como estratégia de formação no estágio supervisionado em ciências e biologia
}

Moraes Viviane R. A. ${ }^{1}$

Categoria 2. Trabalho de investigação

Resumo: Neste trabalho, investigamos uma proposta de formação inicial fundamentada na perspectiva do professor pesquisador no espaço do estágio supervisionado, que visava oportunizar aos licenciandos a investigação sobre a própria prática, transformando-a em objeto de indagação, com sentido crítico e de forma sistemática. Assim, investigamos se as ações geradas pelos trabalhos de pesquisa produzidos constituíram-se como espaços potencialmente promotores de processos relacionados à construção do Conhecimento Pedagógico do Conteúdo (PCK). Nossos resultados mostram que a interlocução entre teoria e prática, no exercício da investigação, oportuniza a reflexão crítica e o raciocínio pedagógico em ação, que estão diretamente relacionados à construção de saberes docentes.

\section{Palavras-chave}

Formação, estágio, pesquisa, PCK.

\section{Introdução}

É no espaço do estágio, que após um período aproximado de 16 anos no papel de aluno, o licenciando fará sua estreia no papel de professor. Embora, ele já possa ter tido contato com as escolas e a docência, o estágio surge como oportunidade para reunir os conhecimentos teóricos adquiridos anteriormente com situações reais de práticas, e assim começar a construir sua identidade docente (Pimenta \& Lima, 2004).

Torna-se importante, portanto, trabalhar o estágio como uma teia de relações histórico-culturais, políticas, epistemológicas, pedagógicas e éticas, que possibilite ao futuro professor estabelecer um diálogo reflexivo entre a teoria estudada e a realidade encontrada. Para tal, existem estudos que apontam a pesquisa no

\footnotetext{
${ }^{1}$ Universidade Federal de Uberlândia - MG/Brasil vivimoraes@inbio.ufu.br
} 
Revista Tecné, Episteme y Didaxis: TED. Año 2014, Número Extraordinario. ISSN Impreso: 0121-3814, ISSN web: 2323-0126 Memorias, Sexto Congreso Internacional sobre Formación de Profesores de Ciencias. 08 al 10 de octubre de 2014, Bogotá

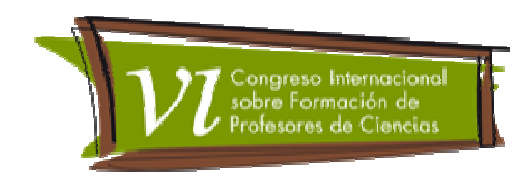

estágio, como uma estratégia de formação capaz de mobilizar as informações de pesquisas realizadas na área, ampliando a análise dos contextos onde os estágios se realizam; como também, pode possibilitar aos licenciandos 0 desenvolvimento da postura e habilidades de pesquisador, a partir da problematização das situações que observa e vivencia na prática. Este tipo de estágio pressupõe outra abordagem diante do conhecimento, considerando-o não mais como verdade absoluta e capaz de explicar toda e qualquer situação observada, mas como algo que pode ser construído, modificado ou ampliado na relação entre as explicações existentes e os novos dados que a realidade fornece quando sistematicamente investigada (Pimenta \& Lima, 2004).

Historicamente, a valorização da pesquisa como método na formação inicial de professores começou no início da década de 1990, a partir do questionamento sobre a indissociabilidade entre teoria e prática, e com a divulgação de propostas fundamentadas na perspectiva do professor-investigador (Stenhouse, 1998), além das contribuições de autores sobre a concepção do professor como profissional reflexivo (Schõn, 2000). Os estudos, dentro destes pressupostos, indicam que a pesquisa no estágio pode proporcionar aos licenciandos um espaço de formação que articula a reflexão sobre a própria prática, a formação de atitudes investigativas, seus conhecimentos de áreas específicas, seus saberes experienciais e conhecimentos de natureza metodológica e sistemática exigidas pelo rigor de uma investigação (Alarcão, 2001).

Neste estudo, investigamos uma proposta de formação, dentro desta perspectiva, em um curso de Ciências Biológicas no qual houve, no espaço do estágio, uma proposta de pesquisa sobre a prática vivenciada. Nosso intuito foi analisar se as ações geradas pelos trabalhos de pesquisa produzidos constituíramse como espaços potencialmente promotores de processos relacionados à construção do Conhecimento Pedagógico do Conteúdo (PCK).

\section{Marco Teórico}

Nas últimas décadas, diferentes modelos de formação têm sido propostos com o objetivo de auxiliar e potencializar o desenvolvimento dos conhecimentos e saberes dos professores em formação inicial. Autores como Shulman (1987), Tardif (2002), e Gauthier (1998) indicam que os espaços de prática são capazes de desencadear processos formativos fundamentais a partir de experiências que articulam o conhecimento do conteúdo, o conhecimento pedagógico e o conhecimento específico da matéria de ensino. 
Revista Tecné, Episteme y Didaxis: TED. Año 2014, Número Extraordinario. ISSN Impreso: 0121-3814, ISSN web: 2323-0126 Memorias, Sexto Congreso Internacional sobre Formación de Profesores de Ciencias. 08 al 10 de octubre de 2014, Bogotá

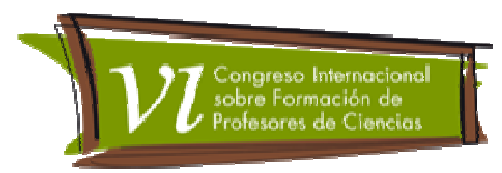

De acordo com Shulman (1987), a confluência entre estes conhecimentos compõem um corpo de compreensões, saberes, habilidades e disposições necessárias para a atuação profissional, constituindo o Conhecimento Pedagógico do Conteúdo (Pedagogical Content Knowledge -PCK). Segundo o autor, a base constituinte desse arcabouço de conhecimentos envolve $O$ raciocínio pedagógico, uma forma complexa do pensamento reflexivo do professor, que tem lugar em vários momentos da sua prática e se traduz em seu envolvimento em ciclos progressivos de pensamento, através dos quais ocorre a transformação do currículo formal em currículo de ensino. (Figura 1).

Figura 1: Modelo de Raciocínio Pedagógico e Ação, adaptado de Shulman (1987).

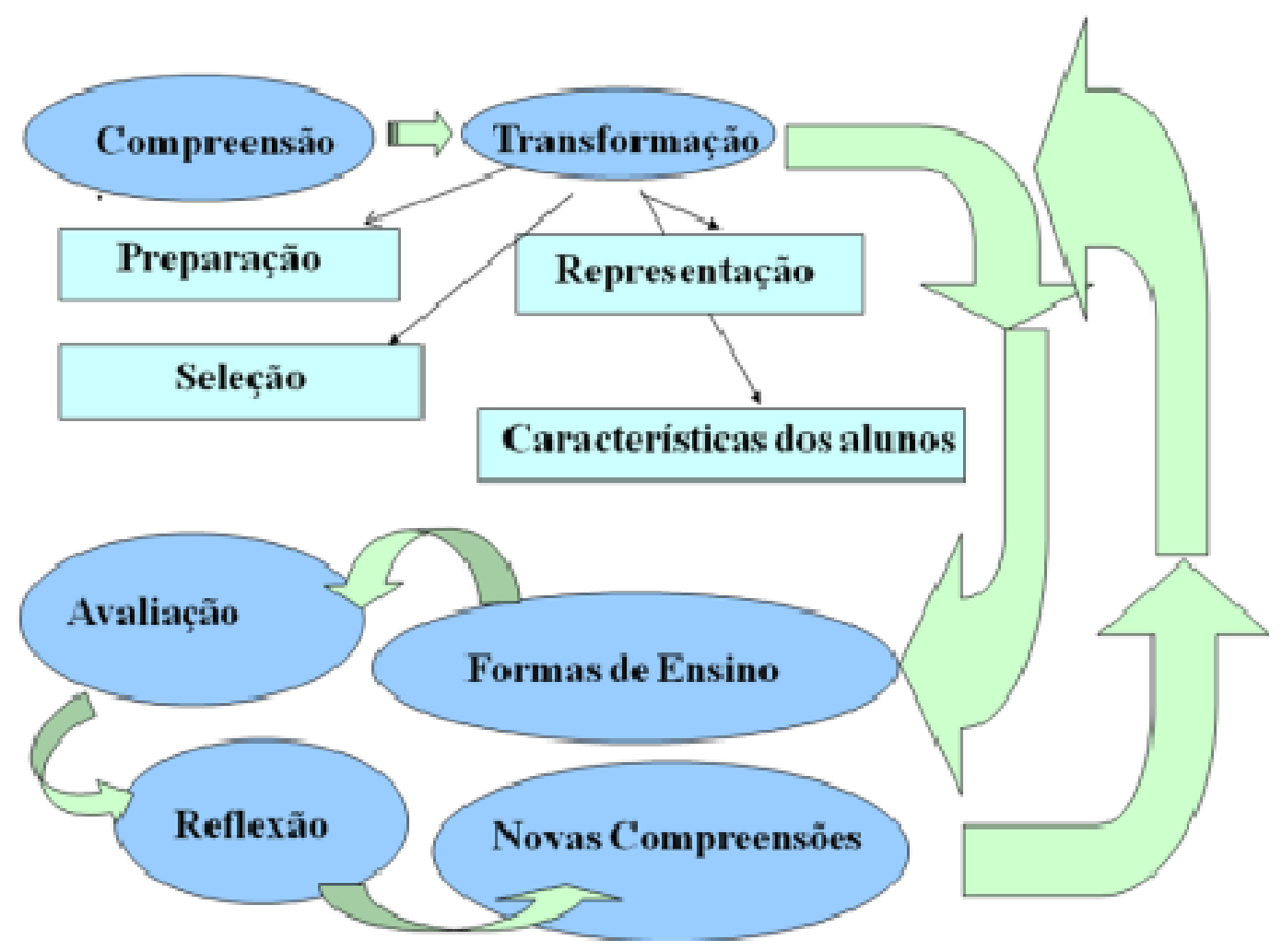

Nesse âmbito, a proposta de estágio aqui investigada, fundamentava-se na proposição de professor-investigador, dentro da abordagem de Pimenta e Lima (2004) sobre a visão do estágio como pesquisa e da pesquisa no estágio. Segundo os autores, o professor como pesquisador de sua própria prática, transforma-a em objeto de indagação dirigida à melhoria de suas qualidades 
Revista Tecné, Episteme y Didaxis: TED. Año 2014, Número Extraordinario. ISSN Impreso: 0121-3814, ISSN web: 2323-0126 Memorias, Sexto Congreso Internacional sobre Formación de Profesores de Ciencias. 08 al 10 de octubre de 2014, Bogotá

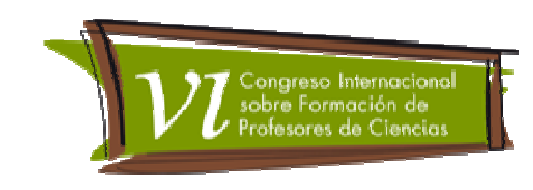

educativas, com sentido crítico e de forma sistemática. Alarcão (2001) considera também que, formar um professor investigador implica desenvolver competências para investigar na, sobre e para a ação educativa e para partilhar resultados e processos com seus pares.

A pesquisa sobre a prática se constituiria, portanto, a partir da reflexão constante e cíclica do raciocínio pedagógico em ação, num processo dialético de geração da prática a partir da teoria, e da teoria a partir da prática, movimentos imprescindiveis para a efetividade da aprendizagem da docência no espaço do estágio.

\section{Metodologia}

Nossa proposta metodológica fundamenta-se na abordagem qualitativa, como um estudo de caso na perspectiva interpretativa. Para Denzin \& Lincoln (2006), um estudo de caso realizado nessa perspectiva, pretende apreender as subjetividades, no qual, o pesquisador se interroga sobre o significado e o sentido que as realidades vivenciadas têm para os sujeitos em questão.

Nessa linha, o contexto estudado foi o segmento Estágio Investigação, no qual o licenciando pôde escolher livremente seu tema de pesquisa dentro dos vários momentos e respectivas atividades vivenciadas durante a disciplina. Dos 21 licenciandos participantes investigamos um sujeito (João), cujo critério de escolha baseou-se no maior número de dados coletados. $O$ instrumento utilizado para coleta de dados foi o diário virtual do licenciando, no qual narrou suas experiências diárias.

Para a análise, definimos categorias baseadas no PCK reformulado por Abell (2007) (Figura 2), que apresenta seus elementos constituintes em 3 dimensões abrangentes subdivididas em: Conhecimento sobre a matéria de ensino (Conhecimento do currículo de ciências); Conhecimento pedagógico (Gestão de classe; Ensino e aprendizagem; Conhecimento sobre avaliação em ciências; Metas educacionais); e Conhecimento do contexto (Alunos; Escola; Comunidade escolar). 
Revista Tecné, Episteme y Didaxis: TED. Año 2014, Número Extraordinario. ISSN Impreso: 0121-3814, ISSN web: 2323-0126 Memorias, Sexto Congreso Internacional sobre Formación de Profesores de Ciencias. 08 al 10 de octubre de 2014, Bogotá

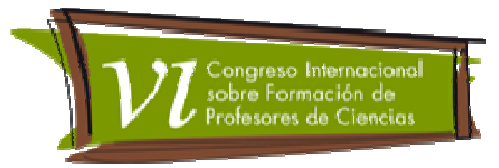

Figura 2: Elementos constituintes do PCK (ABELL, 2007).

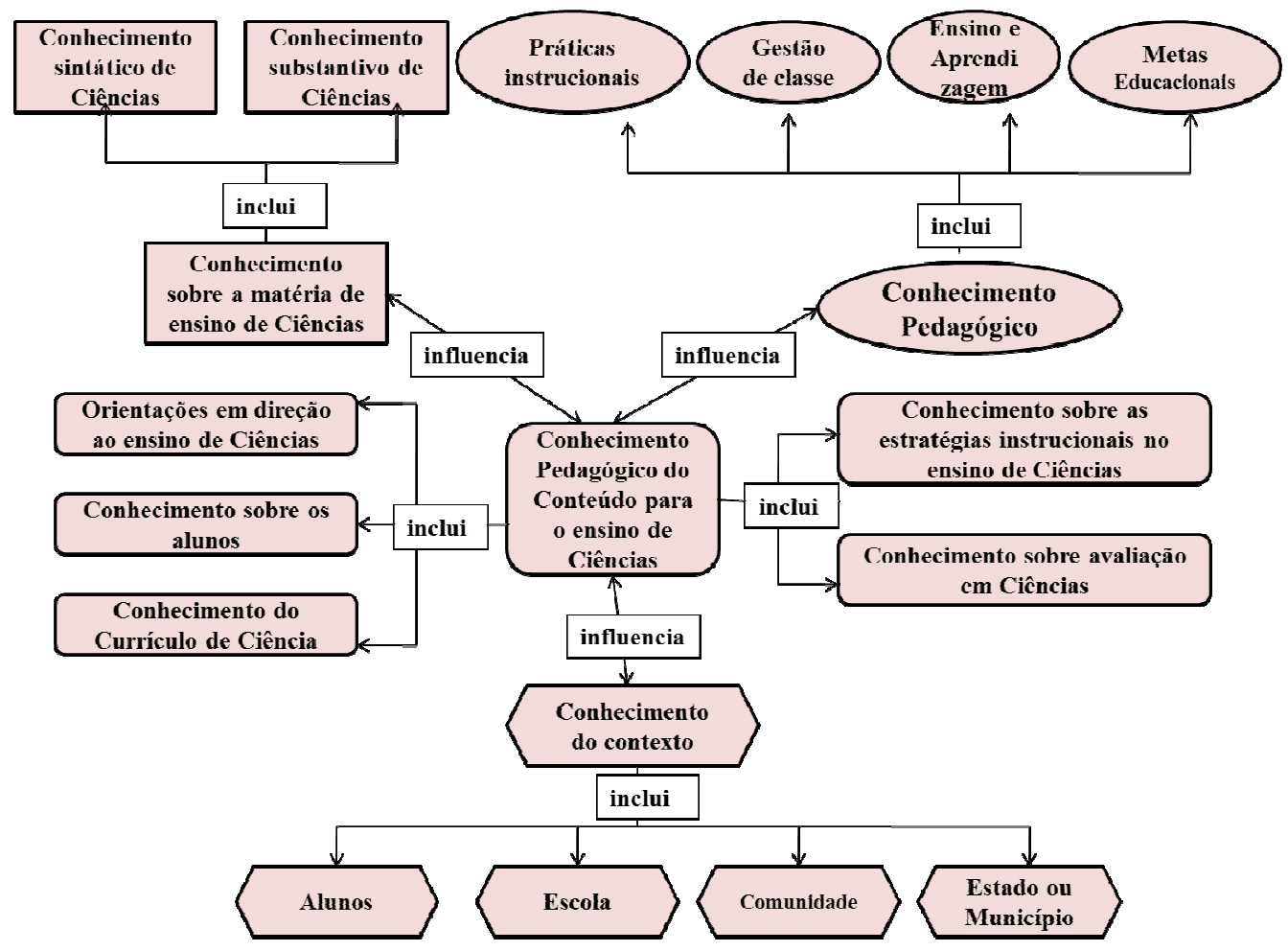

\section{Resultados}

João escolheu seu tema a partir de uma situação de conflito presenciada na escola campo de estágio. $\bigcirc$ título de seu trabalho foi Revisão bibliográfica sobre a educação para menores em conflito com a lei. Percebemos que a investigação de João partiu de motivações afetivas, que remetem às relações pessoais entre professores e alunos no contexto sociopolítico e cultural da escola e seu entorno. Intencionalmente, o licenciado mostrou uma atitude crítica e questionadora indicando a percepção de uma realidade e o desejo de conhecê-la e compreendê-la com mais profundidade, caracterizando o foco afetivo no aluno, o vínculo com a realidade de seu contexto e a repercussão em sua aprendizagem da docência. Além do que, percebemos um desenvolvimento em sua capacidade de organizar sistematicamente os dados levantados durante sua prática investigativa, e clareza durante a apresentação dos mesmos, indicando a elaboração de saberes didáticos gerais sobre ensino/aprendizagem e saberes relativos ao contexto, pois João argumentou que (...) o professor 
Revista Tecné, Episteme y Didaxis: TED. Año 2014, Número Extraordinario. ISSN Impreso: 0121-3814, ISSN web: 2323-0126 Memorias, Sexto Congreso Internacional sobre Formación de Profesores de Ciencias. 08 al 10 de octubre de 2014, Bogotá

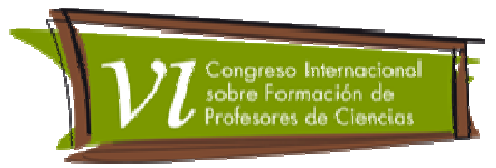

precisa enxergar além do comportamento do aluno em sala, destacando em seu diário que,

(...) o caminho que leva à marginalidade não é traçado por uma categoria particular de crianças e adolescentes, mas sim por todo um conjunto de problemas estreitamente relacionados com condições de habitação subumanas, crises entre os pais, um sentimento generalizado de alienação e de isolamento no seio da família, na escola, e acima de tudo, pela discriminação feita pelas pessoas do seu meio que representam a sociedade dita "normal". (DIÁRIO VIRTUAL DE JOÃO- ESTÁGIO INVESTIGAÇÃO)

Assim, na tentativa de responder aos questionamentos vinculados à sua pergunta de pesquisa, ele ressaltou vários aspectos relacionados: ao ensino: (...) estes educadores não têm formação específica, (...) o que interessa sempre é encarceramento e repressão, medidas de controle mesmo, sabe?; à aprendizagem: (...)um dos grandes problemas dessas instituições é a mistura de idades. Crianças infratoras com crianças abandonadas variando de seis a dezessete anos; ao papel do aluno e do professor, além de estabelecer uma argumentação coerente sobre a rede de implicações sócio-político, cultural e econômica existente entre estes temas.

Dessa forma, João demonstrou a elaboração de saberes que relacionam a percepção de contextos específicos e a atuação diferenciada do professor nestes, a gestão da sala de aula (motivação, disciplina, organização), as práticas instrucionais direcionadas e intencionalmente construídas, bem como, a importância das relações interpessoais e sua repercussão na aprendizagem dos alunos e no desenvolvimento da prática instrucional docente. Nesse âmbito, ressaltamos que João ilustrou o que Zeichner (1993) considera como aspectos constituintes das práticas do professor reflexivo como, analisar e enfrentar os dilemas que se colocavam na sua atividade, assumir os seus valores, estar atento aos contextos culturais e institucionais, envolver-se na mudança e possivelmente tornar-se agente do seu próprio desenvolvimento profissional. Destacamos no quadro abaixo (quadro 1) os elementos do PCK percebidos durante o estágio investigação de João. 
Revista Tecné, Episteme y Didaxis: TED. Año 2014, Número Extraordinario. ISSN Impreso: 0121-3814, ISSN web: 2323-0126 Memorias, Sexto Congreso Internacional sobre Formación de Profesores de Ciencias. 08 al 10 de octubre de 2014, Bogotá

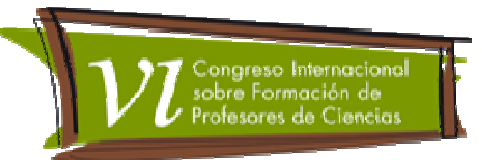

\begin{tabular}{|c|c|c|c|}
\hline \multirow{2}{*}{$\begin{array}{l}\text { TEMA DA } \\
\text { INVESTIGAÇÃO: }\end{array}$} & \multicolumn{2}{|c|}{ ELEMENTOS DOPCK } & \multirow{2}{*}{$\begin{array}{l}\text { DIÁRIO VIRTUAL DE JOÃO - REFLEXÕES } \\
\text { SOBRE O ESTÁGIO INVESTIGAÇÃO }\end{array}$} \\
\hline & $\begin{array}{l}\text { CATEGORIAS } \\
\text { SABERES }\end{array}$ & $\begin{array}{l}\text { SUBCATEGORIAS } \\
\text { SABERES }\end{array}$ & \\
\hline 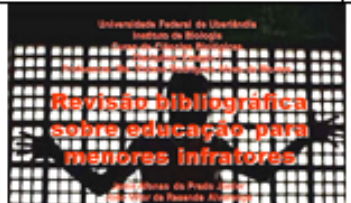 & $\begin{array}{l}\text { Saberes } \\
\text { didáticos ge rais }\end{array}$ & $\begin{array}{l}\text { Ensino e } \\
\text { aprendizagem }\end{array}$ & $\begin{array}{l}\text { (...) um dos grandes problemas dessas } \\
\text { instituições é a mistura de idades. } \\
\text { Crianças infratoras com crianças } \\
\text { abandonadas variando de seis a } \\
\text { dezessete anos. }\end{array}$ \\
\hline 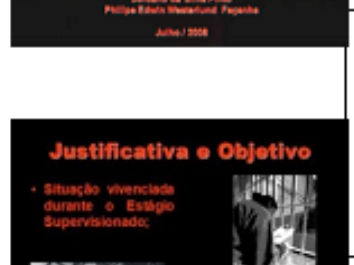 & $\begin{array}{l}\text { Saberes } \\
\text { didáticos } \\
\text { pessoais }\end{array}$ & $\begin{array}{l}\text { Relações } \\
\text { interpessoais } \\
\text { professo/aluno }\end{array}$ & $\begin{array}{l}\text { (...) Teve um caso da professora se ferir } \\
\text { durante uma rebelião. (...) ela preferiu } \\
\text { preservar a identidade para evitar perder } \\
\text { a confiança dos alunos. (...) Esse fato } \\
\text { contrasta como ocomido durante nosso } \\
\text { estágioe mostra o verdadeiro espínto de } \\
\text { um professor. }\end{array}$ \\
\hline 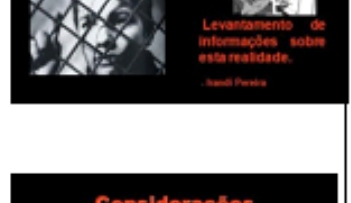 & \multirow[t]{2}{*}{$\begin{array}{l}\text { Saberes sobre } \\
\text { o contexto de } \\
\text { atuação }\end{array}$} & $\begin{array}{l}\text { Contexto familiar } \\
\text { do aluno }\end{array}$ & \multirow{2}{*}{$\begin{array}{l}\text { (...) o caminho que leva à marginalidade } \\
\text { não é traçado por uma categoria } \\
\text { particular de crianças e adolescentes, } \\
\text { mas sim por todo um conjunto de } \\
\text { problemas estreitamente relacionados } \\
\text { com condições de habitação } \\
\text { subumanas, crises entre os pais, um } \\
\text { sentimento generalizado de alienação e } \\
\text { de isolamento no seio da familia, na } \\
\text { escola, e, acima de tudo, pela } \\
\text { discriminação feita pelas pessoas do seu } \\
\text { meio que representam a sociedade dita } \\
\text { "normal". }\end{array}$} \\
\hline 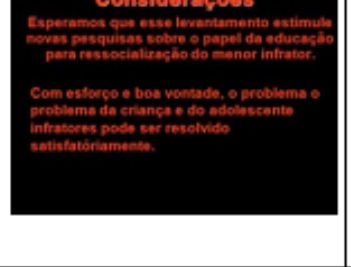 & & $\begin{array}{l}\text { Contexto escolar } \\
\text { (Entomo sócio/ } \\
\text { cultural e } \\
\text { político) }\end{array}$ & \\
\hline
\end{tabular}

\section{Considerações Finais}

Nesse estudo, investigamos se a pesquisa sobre a prática foi, de fato, um espaço potencialmente promotor de processos formativos capazes de evidenciar aspectos relacionados à reflexão crítica e ao raciocínio pedagógico, e sua relação com a aprendizagem da docência.

Percebemos que ao planejar e desenvolver seu projeto de pesquisa, o licenciando racionalizou sobre suas experiências, apresentando indicadores de que havia tomado consciência dos significados vivenciados e lhes atribuído um sentido próprio. Nesse movimento de questionamentos e reflexões sobre as experiências práticas, vimos em suas expressões o desenvolvimento de seu raciocínio pedagógico durante sua ação, bem como, a elaboração de saberes didáticos gerais, sobre o currículo em geral e específico, além de saberes didáticos pessoais e sobre o contexto, que são elementos constituintes do PCK. 
Revista Tecné, Episteme y Didaxis: TED. Año 2014, Número Extraordinario. ISSN Impreso: 0121-3814, ISSN web: 2323-0126

Memorias, Sexto Congreso Internacional sobre Formación de Profesores de Ciencias. 08 al 10 de octubre de 2014, Bogotá

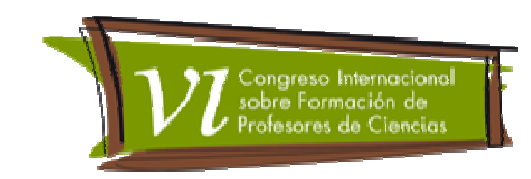

Pensamos que este estudo insere-se na dimensão de ajudar- nos a discutir a maneira como o conhecimento dos professores em formação pode estabelecerse por meio de ações formativas que instiguem a reflexão sistemática, intencional e organizada dentro de projetos de investigação. Reafirmando assim, a valorização das experiências práticas na formação inicial, bem como da pesquisa sobre a mesma, destacando como eixo estruturante os processos reflexivos.

\section{Referências Bibliográficas}

ABELL, S. (2007). Research on science teachers' knowledge. In S. K. ABELL AND N. G. LEDERMAN (Eds.), Handbook of research on science education. Mahwa, New Jersey: Lawrence Erlbaum Associates. p. 1105-1149.

ALARCÃO, I. (2001). Professor-investigador: Que sentido? Que formação? In. B. P. Campos (Ed.) Formação Profissional de Professores no Ensino Superior. Porto: Porto Editora, Vol. 1 (p. 21-31).

DENZIN, N. K.; LINCOLN, Y. S. (org), (2006). O planejamento da pesquisa qualitativa: teorias e abordagens. Artmed, Porto Alegre.

GAUTHIER, C. et al. (1998). Por uma teoria da pedagogia. Editora Unijuí. ljuí.

PIMENTA, S. G.; LIMA, M. S. L. (2004). Estágio e docência. Cortez. São Paulo.

SCHÖN, D. (2000). Educando o profissional reflexivo: um novo design para o ensino e a aprendizagem. Artmed, Porto Alegre.

SHULMAN, L. S. (1987). Knowledge and teaching: foundations of the new reform. Harvard Educational Review, Cambridge, v. 57, n. 1, págs. 1-22.

STENHOUSE, L. (1998). La investigación como base de la enseñanza: selección de textos por J. Rudduck y D. Hopkins. Ediciones Morata. Madrid.

TARDIF, M. (2002). Saberes docentes e formação profissional. Editora Vozes. Petrópolis.

ZEICHNER, K. (1993). Formação Reflexiva de Professores, Ideias e Práticas. EDUCA, Lisboa. 